\title{
lodine deficiency in pregnant women and neonates in Thailand
}

\author{
Rajata Rajatanavin* \\ Department of Medicine, Faculty of Medicine Ramathibodi Hospital, Mahidol University, Bangkok 10400, Thailand
}

\begin{abstract}
Objective: To present data on the relationship between the concentration of thyroidstimulating hormone (TSH) in whole blood or serum from neonates and the concentration of iodine in their mother's urine collected at birth to contribute to the contention that the recommended iodine intake during pregnancy should be increased.

Design and Setting: Data were provided by current programmes of neonatal screening of congenital hypothyroidism in Bangkok and rural areas of Thailand.

Subjects: A total of 5144 cord serum samples were collected in 2003 and measured for TSH concentrations. Paired samples of blood and urine were collected in 2000 from 203 infants and their mothers and from 1182 infant-mother pairs in 2002-03 in six rural provinces. Iodine was measured in the urine and TSH was measured in cord serum. Results: The urinary iodine concentration of mothers in rural Thailand is adequate, with a median of $103 \mu \mathrm{g} \mathrm{l^{-1 }}$. However, in 2000, the median urinary iodine concentration of mothers in Bangkok was only $85 \mu \mathrm{g} \mathrm{l}^{-1}$. The concentration of TSH in whole blood collected on filter paper from neonates was not sensitive enough to be used as a monitoring tool for iodine nutrition in the neonates, as there was no relationship with the concentration of iodine in the urine of the children's mothers. This was in contrast to the concentration of TSH in serum collected from cord blood. Conclusions: Several conclusions were drawn from this data: 1) Neonatal TSH screening using whole blood collected from a heel prick at 3 days of age is not sensitive enough to assess the iodine nutrition of neonates; 2) Neonatal TSH screening using cord sera can be used to assess iodine nutrition in neonates; 3) The optimum median maternal urinary iodine concentration in Thailand appears to be $103 \mu \mathrm{g}^{-1}$; 4) The criteria proposed by WHO, UNICEF, and ICCIDD to assess iodine nutrition using data on neonatal TSH concentrations should be reassessed; and 5) Neonatal TSH screening can be effectively performed by collecting cord serum in district hospitals in Thailand.
\end{abstract}

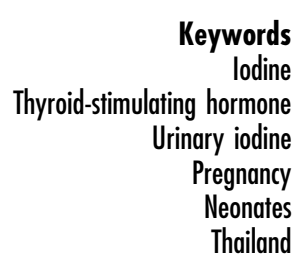

\section{Introduction}

It has recently been suggested that the optimum intake of iodine during pregnancy and lactation should be higher than the amount currently recommended by the WHO, the UNICEF and the ICCIDD $^{1,2}$. The rationale for this is the increased requirement for thyroxine by the mother, the transfer of thyroxine and iodide from the mother to her foetus and the increased renal clearance of iodide ${ }^{3}$. Based on an extensive review of the literature, Delange has suggested that the iodine intake during pregnancy should be increased from 200 to $250-300 \mu \mathrm{g} \mathrm{day}^{-1}$, and during lactation from 200 to $225-350 \mu \mathrm{g} \mathrm{day}^{-1}$.

Neonatal screening for congenital hypothyroidism is not widely used as a monitoring tool to assess the iodine nutrition of populations. We have demonstrated that the concentration of thyroid-stimulating hormone (TSH) in neonates can be used as an indicator of iodine nutrition ${ }^{4}$. It is particularly useful when programmes for monitoring, such as the one operating in Thailand, place an emphasis on the iodine status of schoolchildren. However, it is possible that the goitre rate in schoolchildren may not reflect the iodine status of other members of the population, especially neonates. For example, Table 1 shows the change in goitre rate over a period of 4 years among school children in five districts of Thailand in which an iodine supplementation programme was implemented and is compared with the change in the same districts in the odds ratio among neonates of having a TSH concentration greater than neonates born in Bangkok. The changes were not all in the same direction.

The aim of this paper is to present data from Thailand on the relationship between the concentration of TSH in whole blood or serum from neonates and the concentration of iodine in their mother's urine collected at birth to contribute to the contention that the recommended iodine intake during pregnancy should be increased. The paper also presents experience in Thailand of using the neonatal TSH concentration as an indicator of the iodine nutrition of neonates. 
Table 1 The changes in goitre rate in schoolchildren in five districts of Nan Province, Thailand 4 years after iodine supplementation. Also shown are the changes in the odds ratio among neonates in the same districts of having a thyroid-stimulating hormone concentration greater than neonates in Bangkok.

\begin{tabular}{lcr}
\hline District & $\begin{array}{l}\text { Change in } \\
\text { goitre rate }\end{array}$ & $\begin{array}{l}\text { Change in } \\
\text { odds ratio }\end{array}$ \\
\hline Chaiangklang & -29.5 & -0.70 \\
Muang & -19.4 & -0.25 \\
Pua & -20.7 & 0.40 \\
Tawangpa & -37.2 & 1.20 \\
Wiengsa & -12.6 & -0.75 \\
\hline
\end{tabular}

\section{Methods}

The data were provided by the current programmes of neonatal screening in Bangkok, the capital of Thailand, and from rural areas.

The screening programme for congenital hypothyroidism at Ramathibodi Hospital, Bangkok, which has been in operation since 1993, measures the concentration of TSH in cord serum using an electro-chemiluminescence immunoassay kit from Roche Diagnostics (Mannheim, Germany). The sensitivity of the TSH assay is $0.005 \mathrm{mIUl}^{-1}$.

The concentration of TSH in dried whole blood collected on filter paper in rural hospitals in Thailand is measured by an immunoradiometric assay using kits manufactured in Thailand by the Department of Science, Ministry of Public Health, Bangkok. The sensitivity of the assay for TSH is $0.2-0.9 \mathrm{mIUl}^{-1}$.

The concentration of iodine in urine samples collected from mothers was measured at the endocrine laboratory, Ramathibodi Hospital using method A, the SandellKolthoff reaction, as recommended by the ICCIDD ${ }^{5}$.

\section{Results}

\section{Neonatal cord serum TSH concentration}

A total of 5144 cord serum samples were collected in 2003 at Ramathibodi Hospital, Bangkok and the TSH concentration was measured. Table 2 shows the reference intervals for neonatal serum TSH concentration using centile ranges for the assessment of univariate reference intervals ${ }^{6}$.

Table 2 Classification of the concentration of thyroid stimulating hormone (TSH) in cord serum samples collected from 5114 neonates in Ramathibodi Hospital, Bangkok in 2003. The intervals are derived from reference 6 .

\begin{tabular}{llc}
\hline $\begin{array}{l}\text { Reference interval } \\
\text { of TSH }\left(\mathrm{mIUI}^{-1}\right)\end{array}$ & Classification & Percentage \\
\hline$\leq 7.2$ & Normal & 52.0 \\
$7.3-10.3$ & Mild & 23.7 \\
$10.4-19.6$ & Moderate & 19.7 \\
$>19.6^{*}$ & Severe & 4.6 \\
\hline
\end{tabular}

* $95^{\text {th }}$ percentile.
Neonatal serum TSH and maternal urinary iodine concentrations

In 2000, assays were performed on cord blood and urine samples collected from 203 pairs of infants and their mothers at Ramathibodi Hospital, Bangkok. Figure 1 shows the relationship between the concentration of iodine in the urine of mothers and the concentration of TSH in cord serum.

According to the WHO, the UNICEF and the $\operatorname{ICCIDD}^{7}$, a population has a normal iodine status if $<3 \%$ of neonatal whole blood samples have a TSH concentration of $>5 \mathrm{mIUl}^{-1}$, a value that is equivalent to a serum TSH concentration of $11.2 \mathrm{mIUl}^{-1}$. Figure 2 shows the percentage of serum samples from neonates which had a $\mathrm{TSH}$ concentration greater than this second value according to the concentration of iodine in the urine of paired samples from mothers.

In total, $31 \%$ of serum samples from neonates had a TSH concentration $>11.2 \mathrm{mIUl}^{-1}$, which was in the range of a moderate iodine deficiency according to the WHO/UNICEF/ICCIDD criteria ${ }^{7}$. However, the median urinary iodine concentration of mothers of $85 \mu \mathrm{gl}^{-1}$ fell within the range of a mild iodine deficiency ${ }^{2,7}$.

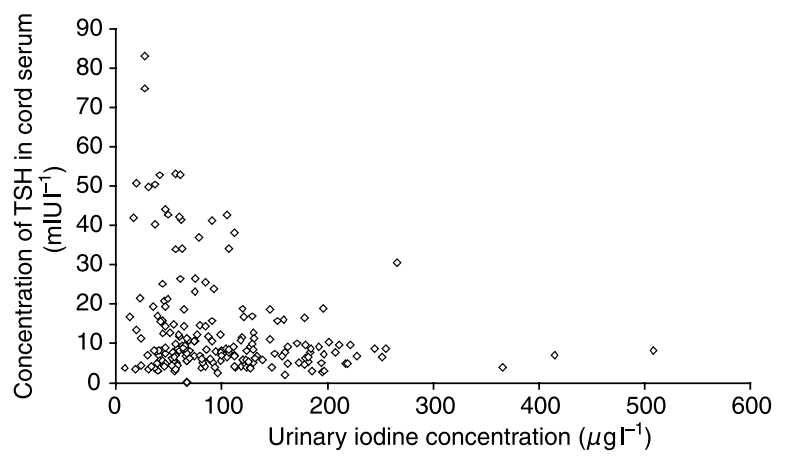

Fig. $1 \mathrm{~A}$ scatter plot of the urinary iodine concentration of mothers and the cord serum concentration of thyroid-stimulating hormone (TSH) from their neonates collected from 203 motherinfant pairs at Ramathibodi Hospital, Bangkok in 2000.

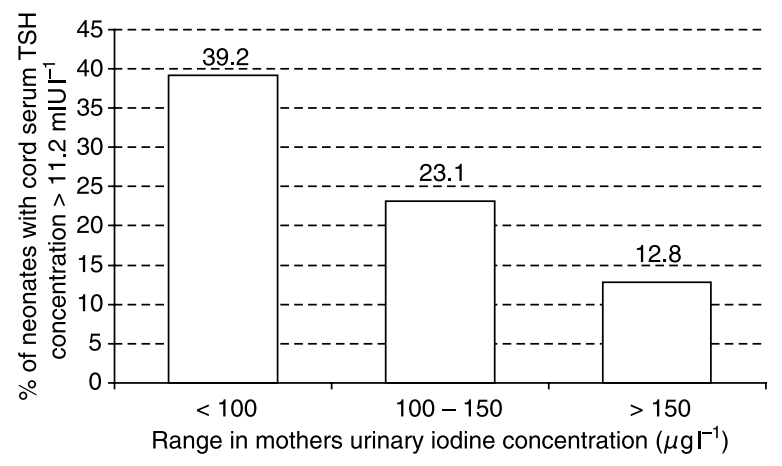

Fig. 2 The percentage of cord serum samples from neonates with TSH concentrations $>11.2 \mathrm{mlUI}^{-1}$, according to the concentration of iodine in the urine of paired samples from mothers. 


\section{Whole blood neonatal TSH concentration}

In contrast to the screening programme at Ramathibodi Hospital, the national neonatal screening programme organised by the Ministry of Public Health, which commenced in 1995, uses dried blood spots collected from a heel prick taken 3 days after birth; the assay for TSH therefore uses whole blood, not cord serum.

Figure 3 shows a scatter plot of the TSH and the iodine concentrations on paired samples of blood and urine collected in 2002-03 from 1182 infants and their mothers in six rural provinces. There was no significant correlation between values.

Figure 4 shows that, in contrast to the data presented in Fig. 2, there was no correlation between the concentration of iodine in the urine of mothers and the concentration of TSH in cord serum.

\section{Maternal urinary iodine concentrations in Thailand}

Periodic monitoring of the prophylactic iodine programme in Thailand started in 2000, when the concentration of iodine in mother's urine was measured at delivery in 15 provinces each year. The provinces were chosen by random cluster sampling from the whole of Thailand. Table 3 shows the median concentration of urinary iodine.

Using a centile chart to assess univariate reference intervals $^{6}$, the median urinary iodine concentration of

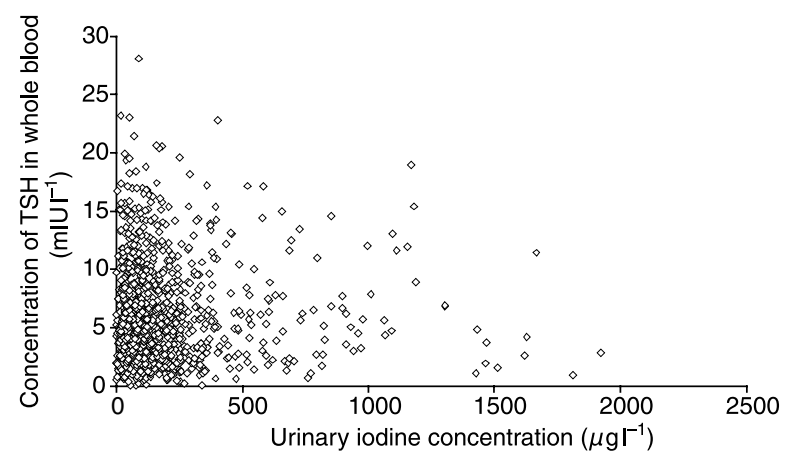

Fig. $3 \mathrm{~A}$ scatter plot of the urinary iodine concentration of mothers and the whole blood concentration of thyroid-stimulating hormone (TSH) from their neonates collected from 1182 motherinfant pairs in Thailand in 2002-03.

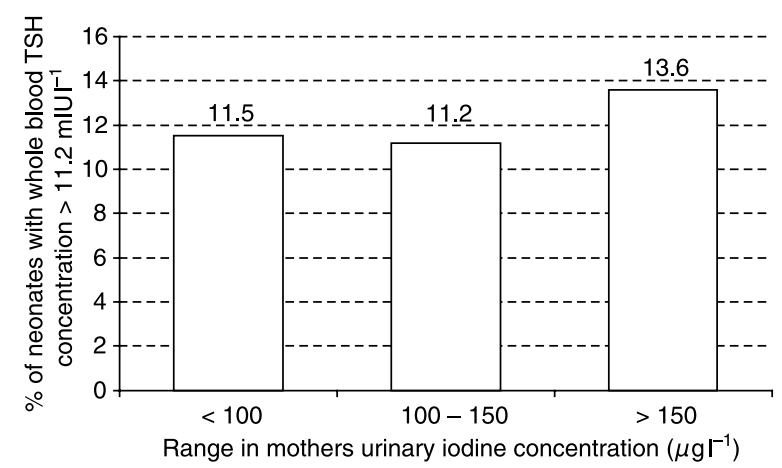

Fig. 4 The percentage of whole blood samples from neonates with a TSH concentration $>11.2 \mathrm{mlUI}^{-1}$ according to the concentration of iodine in the urine of paired samples from mothers.
Table 3 The median concentration of urinary iodine of mothers at delivery derived from periodic monitoring in 15 provinces in four regions of Thailand each year between 2000 and 2003. The data are from the Department of Health, Ministry of Public Health.

\begin{tabular}{|c|c|c|c|c|}
\hline \multirow[b]{2}{*}{ Region } & \multicolumn{4}{|c|}{$\begin{array}{c}\text { Median urinary } \\
\text { iodine concentration }\left(\mu \mathrm{gl}^{-1}\right)\end{array}$} \\
\hline & 2000 & 2001 & 2002 & 2003 \\
\hline North & 173 & 132 & 125 & 108 \\
\hline North-east & 94 & 79 & 93 & 83 \\
\hline Central & 159 & 101 & 108 & 117 \\
\hline South & 196 & 138 & ND* & 192 \\
\hline Total & 153 & 112 & 107 & 115 \\
\hline
\end{tabular}

$\mathrm{ND}^{\star}$, not done.

samples collected from 1182 mothers in 2002-03 was $103 \mu \mathrm{gl}^{-1}$. Applying this concentration to the data collected on the serum TSH concentration of 203 neonates born at Ramathibodi Hospital in 2000, the odds ratio of having a serum TSH concentration greater than the 95th percentile within the same data set $\left(19.6 \mathrm{mIUl}^{-1}\right)$ was 3.2 (95\% CI $1.3,7.8)$, if the mother's urinary iodine concentration was $<103 \mu \mathrm{gl}^{-1}$. This is shown in Table 4 .

In addition, when the odds ratios of having neonatal TSH concentrations $>19.6 \mathrm{mIUl}^{-1}$ were calculated for each centile of the distribution of maternal urinary iodine concentrations, a dose-response relationship was observed (data not shown). However, it was not a significant difference, probably due to the small sample size.

\section{Maternal urinary iodine and neonatal serum TSH concentrations}

Samples of urine from mothers and serum from neonates have been collected at birth on two occasions, 5 years apart, in Dansai district, Loie Province in northern Thailand. It was found that, although the median urinary iodine concentration was $249 \mu \mathrm{gl}^{-1}$ in 1998 and $106 \mu \mathrm{gl}^{-1}$ in 2003 , the median neonatal serum TSH concentration at each survey was not different from that of neonates born in Bangkok (see Table 5).

\section{Discussion}

According to criteria proposed by the WHO, the UNICEF and the $\operatorname{ICCIDD}^{2}$ to assess iodine nutrition, the urinary

Table 4 The odds ratio among 203 neonates born at Ramathibodi Hospital, Bangkok in 2000 of having a serum TSH concentration higher than $19.6 \mathrm{mIUI}^{-1}$ when the mothers urinary iodine concentration was $<103 \mu \mathrm{gl}^{-1}$, which was the median urinary iodine concentration among 1189 rural Thai mothers.

\begin{tabular}{|c|c|c|c|}
\hline \multirow{2}{*}{$\begin{array}{l}\text { Maternal urinary iodine } \\
\text { concentration }\left(\mu \mathrm{gl}^{-1}\right)\end{array}$} & \multicolumn{2}{|c|}{$\begin{array}{l}\text { Neonatal serum } \\
\text { TSH concentration } \\
\left(\mathrm{mlUl}^{-1}\right)\end{array}$} & \multirow{2}{*}{$\begin{array}{l}\text { Odds ratio } \\
(95 \% \mathrm{Cl})\end{array}$} \\
\hline & $<19.6$ & $\geq 19.6$ & \\
\hline $\begin{array}{l}<103 \\
\geq 103\end{array}$ & $\begin{array}{l}98(57 \%) \\
74(43 \%)\end{array}$ & $\begin{array}{r}27(87 \%) \\
4(13 \%)\end{array}$ & $5.1(1.7,15.2)$ \\
\hline
\end{tabular}


Table 5 The median $(95 \% \mathrm{Cl})$ concentration of thyroid stimulating hormone (TSH) in neonates born in 1998 and 2003 in Dansai district, Loie Province, northern Thailand, and the values for neonates in Bangkok in 1994. The median urinary maternal iodine concentration of mothers in Dansai in both years were in the normal range, while the concentration of women in Bangkok was in the range of mild iodine deficiency.

\begin{tabular}{|c|c|c|c|}
\hline & $\begin{array}{c}\text { Dansai } \\
1998\end{array}$ & $\begin{array}{l}\text { Dansai } \\
2003\end{array}$ & $\begin{array}{c}\text { Bangkok } \\
1994\end{array}$ \\
\hline Sample size & 181 & 203 & 1023 \\
\hline $\begin{array}{l}\text { Median TSH concentration } \\
\text { of neonates }\left(\mathrm{mlUl}^{-1}\right)\end{array}$ & $\begin{array}{l}5.75 \\
(5.4,6.3)\end{array}$ & $\begin{array}{l}6.56 \\
(5.5,7.2)\end{array}$ & $\begin{array}{l}5.80 \\
(5.6,6.0)\end{array}$ \\
\hline $\begin{array}{l}\text { Median urinary iodine } \\
\text { concentration of mothers }\left(\mu \mathrm{gl}^{-1}\right)\end{array}$ & 249 & 106 & 85 \\
\hline
\end{tabular}

iodine concentration of mothers in rural Thailand is adequate, with a median of $103 \mu \mathrm{gl}^{-1}$. However, in 2000 , the median urinary iodine concentration of mothers in Bangkok was $85 \mu \mathrm{gl}^{-1}$, which falls in the range of a mild iodine deficiency. The data indicate that a concentration of iodine in the urine of a rural mother of $<103 \mu \mathrm{gl}^{-1}$ was associated with a five-fold greater chance of her neonate having a serum TSH concentration higher than neonates born in Bangkok.

The data shown in Table 5 from Dansai district and Bangkok indicate that there was no substantial difference in the serum TSH concentration of neonates even though the urinary iodine concentration of mothers varied widely from a median of 85 to $249 \mu \mathrm{gl} \mathrm{l}^{-1}$. These data do not seem to support the contention that the iodine intake in pregnancy should increase to $250 \mu \mathrm{gl}^{-1}$ in order to give a corresponding urinary iodine concentration of $150 \mu \mathrm{g} \mathrm{l}^{-1}$.

The data presented in Fig. 3 show that the concentration of TSH in whole blood collected on filter paper from neonates was not sensitive enough to be used as a monitoring tool for iodine nutrition in the neonates, as there was no relationship with the concentration of iodine in the urine of the children's mothers. This was in contrast to the concentration of TSH in serum collected from cord blood. Figure 1 shows a significant relationship between the concentration of TSH in serum from neonates and the concentration of iodine in urine from mothers. In addition, a discrepancy was observed in the same population between two indices of iodine. The proportion of whole blood samples collected from neonates in Bangkok that had a TSH concentration $>5 \mathrm{mIUl}^{-1}$ suggests that Bangkok is an area of moderate iodine deficiency, whereas the median urinary iodine concentration of the mothers of the same children suggested that it was an area of mild iodine deficiency. These findings suggest that the use of the concentration of TSH in whole blood from neonates should be reassessed as an index of iodine nutrition.

\section{Conclusion}

Several conclusions can be drawn from the data from Thailand.

1. Neonatal TSH screening using whole blood collected from a heel prick at 3 days of age is not sensitive enough to assess the iodine nutrition of neonates.

2. Neonatal TSH screening using cord sera can be used to assess iodine nutrition in neonates.

3. The optimum median maternal urinary iodine concentration in Thailand appears to be $103 \mu \mathrm{gl} \mathrm{l}^{-1}$.

4. The criteria proposed by the WHO, the UNICEF and the ICCIDD to assess iodine nutrition using data on neonatal TSH concentrations should be reassessed.

5. Neonatal TSH screening can be effectively performed by collecting cord serum in district hospitals in Thailand.

\section{Acknowledgement}

This work was supported by the Nopparat-Ratanakosin Foundation.

\section{References}

1 Delange F. Optimal iodine nutrition during pregnancy, lactation and the neonatal period. International Journal of Endocrinology and Metabolism 2004; 2: 1-12.

2 WHO, UNICEF, ICCIDD. Assessment of Iodine Deficiency Disorders and Monitoring Their Elimination. A Guide for Programme Managers, 2nd ed. WHO/NHD/01.1. Geneva: World Health Organization, 2001.

3 Smyth PP. Variation in iodine handling during normal pregnancy. Thyroid 1999; 9: 637-42.

4 Rajatanavin R, Unachak K, Winichakoon P, Chailurkit L, Vilasdecanon N, Tananchai P, Srinawat S. Neonatal thyrotropin profile as an index for severity of iodine deficiency and surveillance of iodine prophylactic program. Thyroid 1997; 7: 599-604.

5 Dunn JT, Crutchfield HE, Gute KR, Dunn AD. Two simple methods for measuring iodine in urine. Thyroid 1993; 3: 119-23.

6 Koduah M, Iles TC, Nix BJ. Centile charts I: new method of assessment for univariate reference intervals. Clinical Chemistry 2004; 50: 901-6.

7 WHO, UNICEF, ICCIDD. Indicators for Assessing Iodine Deficiency Disorders and Their Control Through Salt Iodization. WHO/NUT/94.6. Geneva: World Health Organization, 1994. 